\title{
211 電気インピーダンス法による導電率分布の可視化
}

\author{
間渕 周介 ${ }^{\circ}$, 早野 誠治, 齋藤 兆古(法政大学)
}

堀井 清之(白百合女子大学)

\author{
Visualization of Conductivity Distribution \\ by Electrical Impedance Tomography
}

\author{
Shusuke MABUCHI, Seiji HAYANO, Yoshifuru SAITO and Kiyoshi HORII
}

\begin{abstract}
Electrical impedance tomography (EIT) is one of the cheapest ways in order to get a tomography. Principal purpose of the EIT is to obtain a conductivity distribution of a two-dimensional crosssectional target area by injecting the current. EIT utilizes a functional relationship between the injection current and surface potential distribution depending on the conductivity difference. This functional relationship of EIT reveals that EIT has versatile possibilities but it is essentially reduced into solving for an ill-posed inverse problem. In order to develop the EIT, we try to apply the generalized vector sampled pattern matching (GVSPM) method to the inverse problem accompanying with EIT. As an initial test experiment of EIT development, we try to evaluate a resistance distribution in a planer circuit by measuring entire nodal voltages while changing the electrodes for current injection. As a result, it is revealed that a fairly good result could be obtained as an initial test example. Keywords : Generalized vector sampled pattern matching (GVSPM) method, Electrical impedance tomography
\end{abstract}

\section{1. はじめに}

2 次元平面状に存在する物体の投影図を全周辺に亘っ て得られれば, 2 次元平面状に存在する物体の形状が再 現可能である。これが，いわゆるトモグラフィーの基本 的な考え方であり，オーストリアの数学者ラドンによっ て最初に数学的証明がなされ，ラドン変換と呼ばれた. その後, ラドン変換だけでなく, フーリエ変換法や重み 付逆投影法などが開発され，初期は X-線 CT(Computed Tomography), その後, 核磁気共鳴を利用した MRI (Magnetic Resonance Imaging)が開発され，より精緻なト モグラフィーが主として医学分野に広範に用いられてい る.X-線 CT は，対象にX 線を照射した場合の X 線吸収 率を投影図の代わりに用いる。 また，MRI は投影図の代 わりに, 強静磁界下における, 電子の歳差運動に共振す るマイクロ波の吸収率を利用する. 何れも X 線やマイク 口波の吸收率を直接利用寸るため, 数学的根拠も明確で ある。このため，比較的早く開発され，実用に用いられ ている

他方，電気インピーダンス法（EIT）は，X 線やマイ クロ波の変わりに電流を対象に注入し, その結果として 得られる対象の周辺電圧を測定し, 対象の導電率分布を トモグラフィーとして得ようとする．X 線やマイクロ波 は直進性も持つため, 対象の情報が単純な数学的関係で 表現可能である。しかし，EIT では，注入電流に対する 応答は周辺電圧として得られるため, 電磁界の支配方程 式の一種であるラプラス方程式の解として得られる。こ のため，入力とその芯答が境界条件と媒質パラメータで
決まる関数型トモグラフィーとなる. EIT 装置自身は比 較的簡単で安価に構成可能な反面, 注入電流毎に逐次, ラプラス方程式の解を求め, その結果から, 導電率分布 のトモグラフィーを生成する必要がある. 問題は, 電磁 界の支配方程式であるラプラス方程式で媒質を未知とし て解く必要性が有り, いわゆる媒質推定に関寸る逆問題 を逐次解く事に帰する点にある ${ }^{2}$.

本報告では，このような EIT の現状に鑑み，EIT 開発 の第 1 ステップとして, 注入電流に対する応答として得 られる節点電圧が与えられた場合, 平面回路の抵抗分布 がどの程度再現可能かを検討し, その結果, EIT 実現に 関する初期的知見が得られたので此処に報告する。

本報告は，4 章で構成され，第 1 章はまえがきである. 第 2 章は, EIT 問題で遭遇する不適切な線形システムの 解法である一般化ベクトルサンプルドマッチング (Generalized Vector Sampled Pattern Matching GVSPM)法に ついて述べる. 第 3 章は, EIT を集中定数型モデルで置 き換えたシミュレーションと検証実験である。第 4 章は まとめである。

\section{2. 一般化ベクトル型 SPM（GVSPM）法}

\section{1 不適切な線形システム方程式とその正規化}

(1)式の線形システム方程式を考える.

$$
\mathbf{Y}=C \mathbf{X}
$$


ここで， $\mathbf{Y} ， \mathbf{X} ， C$ はそれぞれ $n$ 次の入力ベクトル,$m$ 次の出力ベクトル, $n$ 行 $m$ 列の長方行列である. (1) 式 は次のように書き直すことができる.

$$
\begin{aligned}
\mathbf{Y} & =\sum_{i=1}^{m} x_{i} \mathbf{C}_{i} \\
\mathbf{X} & =\left[\begin{array}{llll}
x_{1} & x_{2} & \cdot & x_{m}
\end{array}\right]^{T} \\
C & =\left[\begin{array}{llll}
\mathbf{C}_{1} & \mathbf{C}_{2} & . & \mathbf{C}_{m}
\end{array}\right]
\end{aligned}
$$

(2) 式を入力ベクトル $\mathrm{Y}$ のノルムで正規化し，(3)式の関 倸が得られる。

$$
\frac{\mathbf{Y}}{|\mathbf{Y}|}=\sum_{i=1}^{m} x_{i} \frac{\left|\mathbf{C}_{i}\right|}{|\mathbf{Y}|} \frac{\mathbf{C}_{i}}{\left|\mathbf{C}_{i}\right|} \text { or } \mathbf{Y}^{\prime}=C^{\prime} \mathbf{X}^{\prime}
$$

(3)式でダッシュ(')は正規化された量を表している。 (3) 式は正規化された入力ベクトル $\mathbf{Y}^{\prime}$ が重み解 $x_{i}\left|\mathbf{C}_{i}\right| /|\mathbf{Y}|$ と 正規化された列べクトル $\mathbf{C}_{i} / \mathbf{C}_{i} \mid$ の線形結合として得られ ることを意味している。ここで $\mathbf{Y}^{\prime} と C^{\prime} \mathbf{X}^{\prime}$ の内積が 1 に なるとき解 $\mathbf{X}$ が得られるということに注意しなければな らない。これが GVSPM 法の基本的な着想である.

\section{2 目標関数}

$k$ 回目の反復解 $\mathbf{X}^{(k)}$ で与えられる $C \mathbf{X}^{(k)}$ と入力ベクトル $\mathbf{Y}$ 間の角度を目標関数 $f\left(\mathbf{X}^{(k)}\right)$ として(4)式で定義する.

$$
f\left(\mathbf{X}^{(k)}\right)=\frac{\mathbf{Y}}{|\mathbf{Y}|} \bullet \frac{C \mathbf{X}^{(k)}}{\left|C \mathbf{X}^{(k)}\right|}=\mathbf{Y}^{\prime} \bullet \frac{C^{\prime} \mathbf{X}^{(k)}}{\left|C^{\prime} \mathbf{X}^{(k)}\right|}
$$

(4)式で, 目標関数 $f\left(\mathbf{X}^{(k)}\right)$ が 1 に収束する時, (1)式の解 $\mathbf{X}$ が求まることを意味する。

$$
f\left(\mathbf{X}^{(k)}\right) \rightarrow 1
$$

(5)式が GVSPM 法の目標関数である。

\section{3 反復解法}

反復解の初期値を $\mathbf{X}^{(0)}$ として(6)式で与える。

$$
\mathbf{X}^{\prime(0)}=C^{\prime T} \mathbf{Y}^{\prime}
$$

(6)式から，最初の偏差べクトル $\Delta \mathbf{Y}^{(1)}$ が(7)式で与えられ る.

$$
\Delta \mathbf{Y}^{\prime(1)}=\mathbf{Y}^{\prime}-\frac{C^{\prime} \mathbf{X}^{(0)}}{\left|C^{\prime} \mathbf{X}^{(0)}\right|}
$$

(7)式で，偏差 $\Delta \mathbf{Y}^{\prime}$ がゼロベクトルであれば，(5)式の目 標関数は自動的に満足される. (7)式を一般化し, 第 $k$ 回 目の反復解ベクトル $\mathbf{X}^{{ }^{(k)}}$ は, 第 $k-1$ 回目の偏差ベクトル $\Delta \mathbf{Y}^{(k-1)}$ を用いて (8)式で与えられる.

$$
\begin{aligned}
\mathbf{X}^{\prime(k)} & =\mathbf{X}^{\prime(k-1)}+C^{\prime T} \Delta \mathbf{Y}^{\prime(k-1)} \\
& =C^{\prime T} \mathbf{Y}^{\prime}+\left(I_{m}-\frac{C^{\prime T} C^{\prime}}{\left|C^{\prime} \mathbf{X}^{\prime(k-1)}\right|}\right) \mathbf{X}^{\prime(k-1)}
\end{aligned}
$$

ここで, $I_{m}$ は $m$ 行 $m$ 列の単位行列である.

\section{4 収束条件}

線形システム方程式の反復解法の収束条件は，(8)式の 状態遷移行列において，すべての固有值が 1 未満でなけ ればならない. (8)式の状態遷移行列 $S$ は(9)式で与えら れる。

$$
S=I_{m}-\frac{C^{\prime T} C^{\prime}}{C^{\prime} \mathbf{X}^{\prime(k-1)}}=I_{m}-\frac{C^{\prime T} C^{\prime}}{\mathbf{Y}^{\prime(k-1)}}
$$

(9)式の入力ベクトル $\mathbf{Y}^{(k-1)}$ のノルムは 1 であるから， (9) 式は次のように書き直すことができる。

$$
S=I_{m}-C^{\prime T} C^{\prime}
$$

ここで入を(10)式の状態遷移行列 $S$ の固有值とすれば, $C^{, T} C^{\prime}$ の対角線要素が全て 1 である事に注意して, 固有 值入は(11)の行列式で与えられる.

$$
\left|\lambda I_{m}-S\right|=\left|\begin{array}{cccc}
\lambda & \varepsilon_{12} & \cdot & \varepsilon_{1 m} \\
\varepsilon_{12} & \lambda & \cdot & \varepsilon_{2 m} \\
\cdot & \cdot & \cdot & \cdot \\
\varepsilon_{1 m} & \varepsilon_{2 m} & \cdot & \lambda
\end{array}\right|=0
$$

(11)式で, 行列 $C^{\prime}$ は正規化された列ベクトル $\mathbf{C}_{i} /\left|\mathbf{C}_{i}\right|$ から なるため, 非対角要素の係数は 1 末満の值をとることは 明らかである。すなわち,

$\left|\varepsilon_{i j}\right|<1$

$i=1,2, \ldots, m, j=1,2, \ldots, m$

となる。(12)式から，収束条件|入k1 が満たされること が判る。拠って, GVSPM 法は常に安定した反復解を与 えることが証明された ${ }^{3)}$.

\section{EIT の集中定数型モデル}

ここでは，実際の EIT を集中定数型電気抵抗回路モデ ルに置き換えて，原理検証を行う。

\section{1 線形システム方程式}

簡単化のため, Fig.1 に示す抵抗回路を考える.

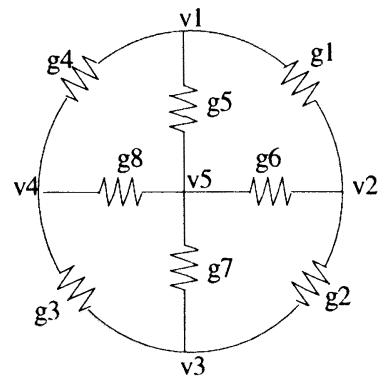

Fig. 1 Electrical Circuit with 5 Nodes, 8 Resistances

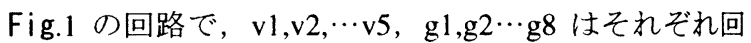
路に電流を注入した場合の各節点電位と各枝のコンダク タンスである。

Fig. 1 で，節点 1 と 3 の間に電流 $I$ を注入したとする. この場合, 節点方程式はv3 を基準電位とすると(13)式で 与えられる。

$$
\begin{aligned}
& \left(v_{1}-v_{2}\right) g_{1}+\left(v_{1}-v_{4}\right) g_{4}+\left(v_{1}-v_{5}\right) g_{5}=I \\
& \left(v_{2}-v_{1}\right) g_{1}+v_{2} g_{2}+\left(v_{2}-v_{5}\right) g_{6}=0 \\
& -v_{2} g_{2}-v_{4} g_{3}-v_{5} g_{8}=-I \\
& \left(v_{4}-v_{3}\right) g_{3}+\left(v_{4}-v_{1}\right) g_{4}+\left(v_{4}-v_{5}\right) g_{8}=0 \\
& \left(v_{5}-v_{1}\right) g_{5}+\left(v_{5}-v_{2}\right) g_{6}+v_{5} g_{7}+\left(v_{5}-v_{4}\right) g_{8}=0
\end{aligned}
$$


(13)式を書き直すと(14)式となる.

$\left[\begin{array}{cccccccc}v_{1}-v_{2} & 0 & 0 & v_{1}-v_{4} & v_{1}-v_{5} & 0 & 0 & 0 \\ v_{2}-v_{1} & v_{2}-v_{3} & 0 & 0 & 0 & v_{2}-v_{5} & 0 & 0 \\ 0 & -v_{2} & -v_{4} & 0 & 0 & 0 & -v_{5} & 0 \\ 0 & 0 & v_{4}-v_{3} & v_{4}-v_{1} & 0 & 0 & 0 & v_{4}-v_{5} \\ 0 & 0 & 0 & 0 & v_{5}-v_{1} & v_{5}-v_{2} & v_{5} & v_{5}-v_{4} \\ g_{5} \\ g_{6} \\ g_{7} \\ g_{8}\end{array}\right]=\left[\begin{array}{c}g_{1} \\ g_{2} \\ g_{3} \\ g_{4} \\ 0 \\ 0 \\ -I \\ 0 \\ 0\end{array}\right]$

(14)式で, コンダクタンス $\mathrm{gl}, \mathrm{g} 2 \cdots \mathrm{g} 8$ が解ベクトルを構 成するから，この場合，式の数が 5 個，未知数が 8 個の 不適切な線形システムを解くこととなる ${ }^{4)}$.

3.2 シミュレーション

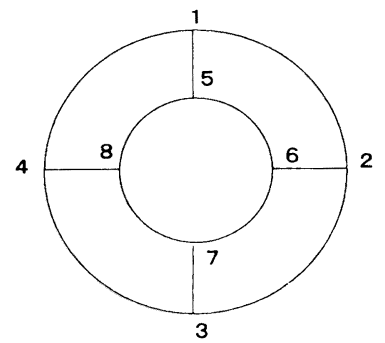

Fig. 2 A Simulation Model

Fig. 2 に示才網状回路を仮定し, 節点 1 と 3 の間に電 流を注入した場合の各節点電位から全抵抗の抵抗值を求 める問題を考える.
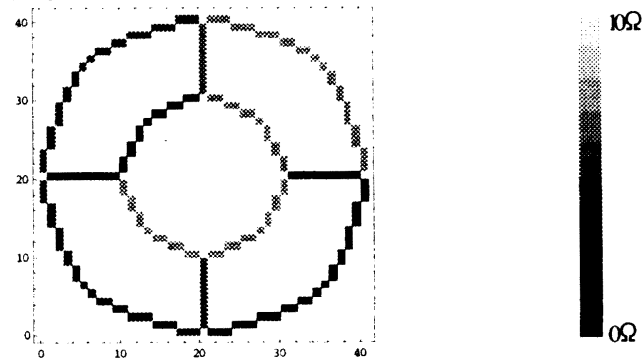

Fig. 3 Assumed Conductance Distribution シミュレーションに用いた抵抗值は乱数で生成した。 その結果をFig. 3 に示す. 抵抗值はFig. 3 に示すように, 明るいほど抵抗值は大きき, 暗いほど小さい。この表示 形式は以後の図においても同様とする.

3.1 節の(14)式で述べた方法で, 線形システム方程式を 導き, 得られた線形システム方程式を GVSPM 法で解き, 抵抗分布を求める.

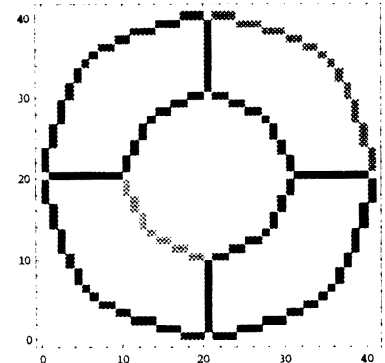

$10 \Omega$

ig. 4 Conductance Distribution Evaluated from a System Having $8 \times 12$ System Matrix
Fig. 4 に GVSPM 法で得られた抵抗分布を示す. 明ら かに正しい解が得られていないことがわかる。これは (14)式のように末知数が既知数よりも多いため, GVSPM 法で数学的に解くことは可能であるが, 必ずしも得られ た解が物理系の抵抗值と一致しない例である.

この問題を解決するため, Fig. 3 で電流を注入する電 極対を増加し，それぞれに対して線形システム方程式を (14)式と同様に導き, それらを合成して全体としての線 形システム方程式を導く。この場合，何れの電流を注入 する電極対に対しても解ベクトルを構成するコンダクタ ンスは共通であるから, 式の数 (情報) は増加し, 未知 数は変わらない。

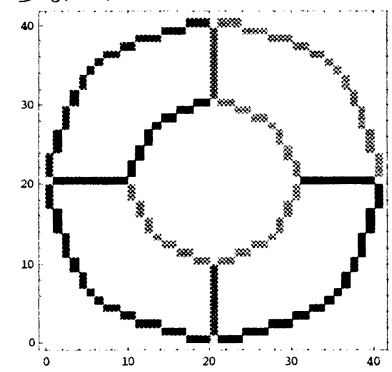

$10 \Omega$

Fig. 5 Conductance Distribution Evaluated from a System Having $16 \times 12$ System Matrix 本シミュレーション例では，電流を注入する電極対を 節点 1 と 3 , および節点 2 と 3 とした。 この場合, 式の 数は 16 個，末知数の数は 12 個となる. すなわち, 16 行 12 列の長方システム行列を持つ不適切な線形システム を GVSPM で解く. Fig. 5 が結果である. Fig. 3 と比較 寸れば，明らかに正しい抵抗分布が得られていることが わかる。

以上のシミュレーション結果から，電流を注入する電 極対数を増加し，対象とする回路の応答情報を増加する ことで物理的に存在する解, すなわち, 抵抗分布卜モグ ラフィーが可能であることが判明した。

\section{3 実験}

Fig. 6 は実験に用いた節点数 24, 抵抗数 40 の回路を 示す.Fig. 7 はFig. 6 の供試回路の抵抗值分布を示す.

Fig.6,7 で，節点番号は外側の頂点を 1 とし，時計回り に順に内側方向一 $1,2 \cdots 24$ として, 番号付けを行う. 基 淮電位を第 5 節点とし，電極対 5-1，5-2，5-3，5-4 とし て，電流を注入する．本実験では，抵抗值分布を得るた めに, 96 行 40 列のシステム行列を持つ線形システム方 程式を GVSPM 法で解くこととになる. Fig.8 に結果を示 す.

Fig. 8 の抵抗分布はFig. 7 の抵抗分布と完全に一致し ていない. 3.2 節で述べたシミュレーション結果によれ ば情報量を増加すれば精度向上が期待できる. 従って, 最外周の 7 電極対を 1 周 (8 電極) させて, 各節点電圧 （1 電極対に対して 24 節点）の電圧を測定し，それらを すべて連立させることで情報量を増加する．すなわち， 1344 行 40 列のシステム行列を持つ方程式を GVSPM を 用いて解く ${ }^{5)}$.

その結果を Fig. 9 に示す. Fig. 9 の結果は, 情報量の 増加が抵抗分布の対称性と值の違いを明確とするが, 必 ずしも精度が向上しないことを意味する。 


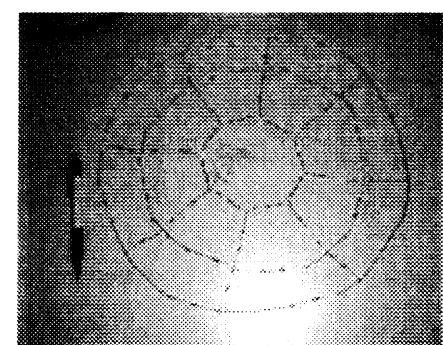

Fig. 6 The Circuit Used for the Experiment

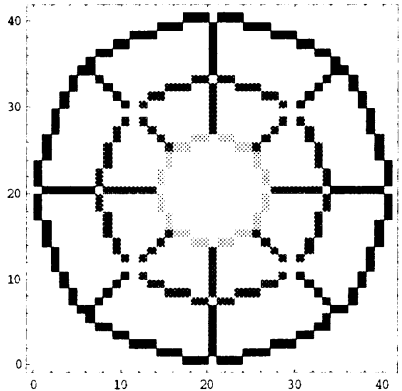

$3 \Omega$

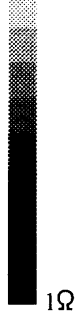

Fig. 7 Conductance Distribution Used for the Experiment

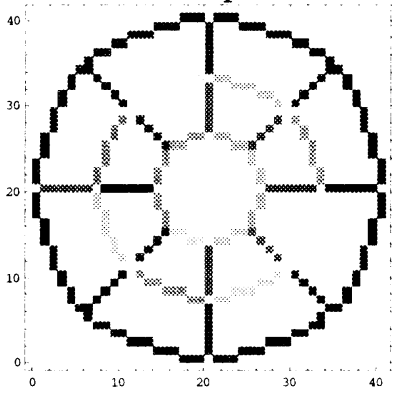

$3 \Omega$

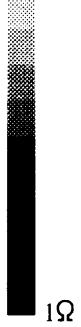

Fig. 8 Conductance Distribution Evaluated from a System Having $96 \times 40$ System Matrix

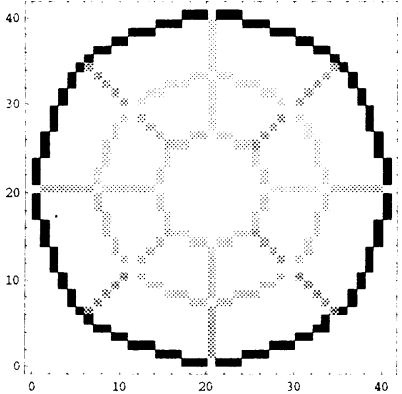

$3 \Omega$

Fig. 9 Conductance Distribution Evaluated from a System Having $1344 \times 40$ System Matrix

情報量の増加は必ずしも高精度な結果に慗がらない原 因は, 情報が実験によって得られているため, 誤差を含 むことに起因すると考えられる．換言すれば，情報量を 增加しても誤差が多く含まれる場合は無意味である。実 験值に含まれる誤差を削減する一方途として, 加算平均 演算が行われる.ここでは, 最外周の 7 電極対に対して 得られる情報を, 各電極対毎に独立して得られた抵抗分 布の加算平均処理を行う。

Fig. 10のその結果を示す. 明らかに, Fig. 7とよく一 致した抵抗分布である.

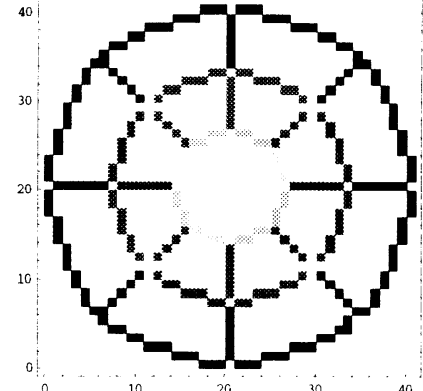

Fig. 10 Conductance Distribution Evaluated by Averaging Operation

\section{4. まとめ}

本論文では，EIT の基礎実験として，抵抗率分布を回 路モデルで置き換え，注入電流と節点電圧から抵抗分布 を推定した。そ結果, シミュレーションでは妥当な結 果が得られた。

しかし，実際の実験では，測定に誤差を伴うため，す べての電極対の組み合わせても良好な結果が期待出来な いことを述べた.

実験値に含有される測定誤差の影響は加算平均処理で 効果的に削減可能であることを述べた。

\section{参考文献}

1) Avinash C. Kak and Malcolm Slaney : Principles of Computerized Tomographic Imaging, The Institute of Electrical and Electronics Engineers, Inc. 1988.

2) Tian Haiyan and et al,: A Study of Reconstruction Algorism of Electrical Impedance Tomography, Proceedings of $2^{\text {nd }}$ Japan Australia New Zealand Joint Seminar on Applied Electromagnetodynamics, KANAZAWA, Jan. 24-25 2002 (to be appeared)

3) H. Endo, S. Hayano and Y. Saito: Generalized Vector Sampled Pattern Matching Method part-1: Theoretical Background, Japan society of Applied Electromagnetics and mechanics, ENDE, May $17-19^{\text {th }}, 2001$, Kobe

4) D. Sekijima, S. Hayano and Y. Saito: Time-Domain Visualization of Quasi-3D Current Vector Distributions, Proceedings of PSFVIP-3, F3303, March 18-21 ${ }^{\text {th }} 2001$, Maui, Hawaii, U.S.A.

5) S. Mabuchi, S. Hayano, Y. Saito, I. Marinova: Generalized Vector Sampled Pattern Matching Method for Inverse Parameter Problems, Proceedings of $2^{\text {nd }}$ Japan Australia New Zealand Joint Seminar on Applied Electromagnetodynamics, KANAZAWA, Jan. 24-25 2002 (to be appeared). 